\title{
Thermal emittance and lifetime of alkali-antimonide photocathodes grown on GaAs and molybdenum substrates evaluated in a $-300 \mathrm{kV}$ dc photogun
}

\author{
Y. Wang $\odot,{ }^{1,2}$ M. A. Mamun, ${ }^{1}$ P. Adderley, ${ }^{1}$ B. Bullard, ${ }^{1}$ J. Grames $\odot,{ }^{1}$ J. Hansknecht,${ }^{1}$ \\ C. Hernandez-Garcia $\odot,{ }^{1}$ R. Kazimi, ${ }^{1}$ G. A. Krafft,,${ }^{1,2}$ G. Palacios-Serrano $\odot,{ }^{2}$ M. Poelker, ${ }^{1}$ \\ M. L. Stutzman $\odot,{ }^{1}$ R. Suleiman $\odot,{ }^{1}$ M. Tiefenback, ${ }^{1}$ S. Wijethunga $\odot,{ }^{2}$ \\ J. Yoskowitz ${ }^{2}{ }^{2}$ and S. Zhang ${ }^{1}$ \\ ${ }^{1}$ Thomas Jefferson National Accelerator Facility, Newport News, Virginia 23606, USA \\ ${ }^{2}$ Old Dominion University, Norfolk, Virginia 23529, USA
}

(Received 1 July 2020; accepted 9 September 2020; published 7 October 2020)

\begin{abstract}
$\mathrm{Cs}_{x} \mathrm{~K}_{y} \mathrm{Sb}$ photocathodes grown on GaAs and molybdenum substrates were evaluated using a $-300 \mathrm{kV}$ dc high voltage photogun and diagnostic beam line. Photocathodes grown on GaAs substrates, with varying antimony layer thickness (estimated range from $<20 \mathrm{~nm}$ to $>1 \mathrm{um}$ ), yielded similar thermal emittance per rms laser spot size values $(\sim 0.4 \mathrm{~mm} \mathrm{mrad} / \mathrm{mm})$ but very different operating lifetime. Similar thermal emittance was obtained for a photocathode grown on a molybdenum substrate but with markedly improved lifetime. For this photocathode, no decay in quantum efficiency was measured at $4.5 \mathrm{~mA}$ average current and with peak current $0.55 \mathrm{~A}$ at the photocathode.
\end{abstract}

DOI: 10.1103/PhysRevAccelBeams.23.103401

\section{INTRODUCTION}

Free electron lasers [1], energy recovery linacs [2] and electron-cooling [3] applications require unpolarized electron beams with high bunch charge (many nano-Coulombs) and high average current (tens to hundreds of milliamperes). For these applications, alkali-antimonide photocathodes are the photocathodes of choice because they provide high quantum efficiency and are less sensitive to ion bombardment than GaAs photocathodes. Alkali-antimonide photocathodes are prompt emitters with relatively low thermal emittance, thus capable of generating bright beams suitable for light source applications [4], and perhaps even for ultrafast electron diffraction applications if fabrication techniques can provide a sufficiently smooth surface $[5,6]$.

Photodetectors employ transmission-mode photocathodes fabricated on transparent substrates, whereas electron guns typically employ reflection-mode photocathodes grown on a variety of electrically conductive substrates [7]. There are a number of documented recipes for fabricating $\mathrm{Cs}_{x} \mathrm{~K}_{y} \mathrm{Sb}$ photocathodes for dc high voltage photoguns [8-14]. Chemicals can be applied to the substrate at the same time (codeposition) or sequentially, using a variety of chemical sources that contain one, two or all three of the chemical species. Besides substrate type and

Published by the American Physical Society under the terms of the Creative Commons Attribution 4.0 International license. Further distribution of this work must maintain attribution to the author(s) and the published article's title, journal citation, and DOI. chemical delivery system, the temperature of the substrate factors into each recipe [15]. Ultimately, for photoguns, the three most important defining metrics of the photocathode are quantum efficiency $(\mathrm{QE})$, thermal emittance and charge lifetime.

At Jefferson Lab, a two-step sequential deposition via thermal evaporation has been employed, with antimony deposited first followed by application of cesium and potassium at the same time from an effusion source containing both species. Past work at Jefferson Lab included surface science evaluation of the foundational antimony layer as a function of antimony deposition time [16]. For long deposition times - which we reasonably assume correlates to a thicker Sb layer-the antimony exhibited crystalline structure with micron-size dimensions, suggesting that thick alkali-antimonide photocathodes would be very rough and have relatively large thermal emittance [17]. However, this work shows that photocathodes fabricated with different $\mathrm{Sb}$ thicknesses over an estimated range $<20 \mathrm{~nm}$ to $>1 \mu \mathrm{m}$ provided similar thermal emittance per rms laser spot size, and similar to values reported in literature of nominally "thin" photocathodes, namely $0.4 \mathrm{~mm} \mathrm{mrad} / \mathrm{mm} \mathrm{[4]} \mathrm{to}$ $0.5 \mathrm{~mm} \mathrm{mrad} / \mathrm{mm}$ [18-21]. These measurements are consistent with recent measurements at $\mathrm{x}$-ray light sources that indicate photocathode formation to be an exothermic reaction, with the $\mathrm{Sb}$ foundational layer completely transformed in the process [22].

\section{PHOTOGUN}

The $-300 \mathrm{kV}$ photogun used for these photocathode studies is described in detail in Ref. [23]. The photogun 
employs an "inverted insulator" geometry, with voltage applied using a high voltage cable that inserts into a conical-shaped alumina insulator. The insulator extends into the vacuum chamber and supports the cathode electrode. The spherical cathode electrode includes a specially designed screening electrode that reduces the electric field strength at the triple-point junction where arcing is thought to originate [23]. The drive laser beam passes through entrance and exit holes in the anode electrode at $25^{\circ}$ angles of incidence and reflection, thereby eliminating the need for in-vacuum laser mirrors which can restrict the effective aperture of the beam line. The anode is electrically isolated from ground potential using alumina washers to enable biasing as a means to repel downstream ions created by the beam [23]. The vacuum pressure inside the photogun while delivering electron beam is about $1 \times 10^{-11}$ Torr achieved using nonevaporable getter and ion pumps.

The spherical electrode has a front face with $1.3 \mathrm{~cm}$ opening and $25^{\circ}$ Pierce focusing geometry. The photocathode is held against the back of the focusing faceplate using spring-loaded sapphire rollers. The electric field strength at the photocathode reaches $2.2 \mathrm{MV} / \mathrm{m}$ when the cathode is biased at $-300 \mathrm{kV}$.

The focusing electrode and the side-insulator design introduce field nonuniformity at the photocathode surface and within the cathode/anode gap that can impact measured values of emittance. However, the emittance was measured and found to be uniform across a significant portion of the photocathode [24]. For comparative evaluation of thermal emittance for different photocathode samples, beam always originated from the center of the active area fabricated off axis by 1 to $2 \mathrm{~mm}$ relative to the photocathode substrate center.

\section{PHOTOCATHODE DEPOSITION CHAMBER}

$\mathrm{Cs}_{x} \mathrm{~K}_{y} \mathrm{Sb}$ photocathodes were manufactured in a vacuum chamber (Fig. 1) designed to accommodate up to five molybdenum sample holders, called pucks, where each puck supports one photocathode substrate. Pucks are cylindrical and cup shaped with a front face that accepts a $1.5 \times 1.5 \mathrm{~cm}$ substrate and a hollow back that accepts a heater and sample manipulator for puck movement. There are two internal puck heaters: bottom heater capable of reaching high temperature for removing residual chemicals on the substrate (i.e., substrate cleaning), and top heater for maintaining the photocathode substrate at an elevated temperature during photocathode fabrication. The heaters are inserted into the recess of the puck using bellows linear-motion translation stages. For substrate cleaning, the puck faces up, and for photocathode fabrication the puck faces down. A 304L stainless-steel paddle with three holes $(3,5$, and $7 \mathrm{~mm}$ diameter) can be rotated into position between the chemical sources and the substrate to limit the dimensions of the active area and to position it off axis by 1 to $2 \mathrm{~mm}$ relative to the photocathode substrate center. The paddle can also be adjusted up and down through a linear-motion translation stage-see Fig. 2. Further details on the deposition chamber are reported elsewhere [23].

Photocathodes were fabricated using a two-step sequential deposition technique similar to that described in Refs. [16,25]. The chemical sources were moved below the puck substrate, one source at a time. Antimony was deposited first from a heated crucible containing Sb pellets. The alkali metals cesium and potassium were codeposited using an effusion source containing both species.

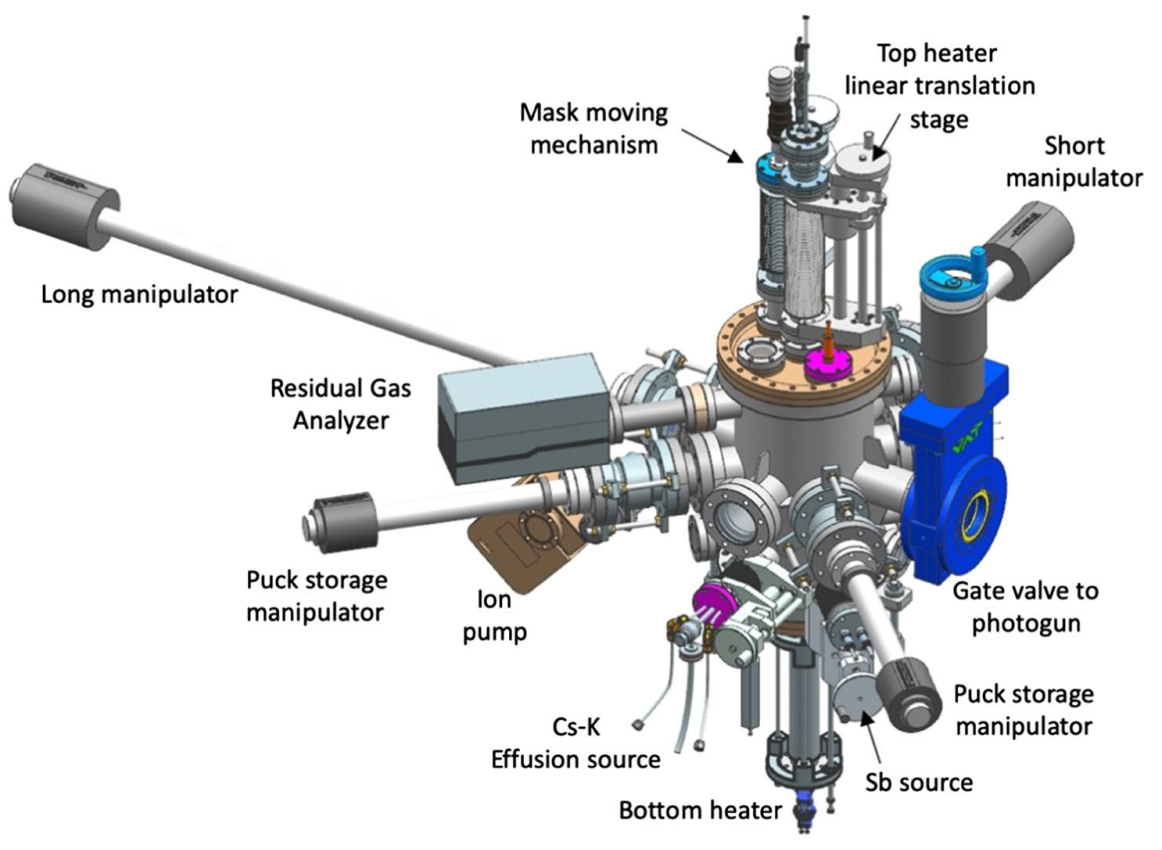

FIG. 1. Photocathode deposition chamber. 

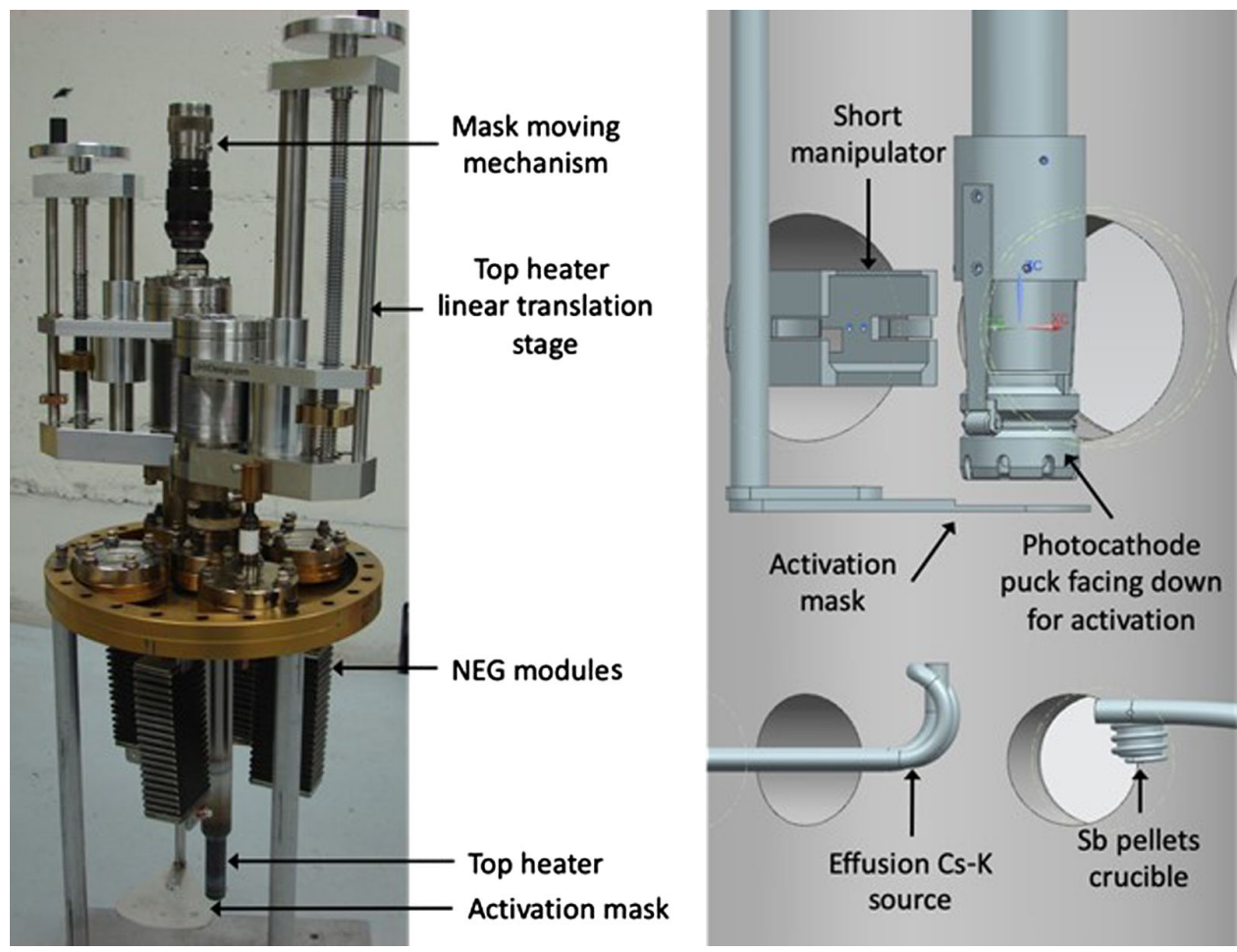

FIG. 2. Left: photograph of the top flange of the photocathode deposition chamber. Right: schematic of the photocathode deposition vacuum chamber internal components showing the photocathode puck facing down behind the mask for photocathode fabrication.

Photocathodes were fabricated on GaAs and molybdenum substrates firmly attached to the pucks using a tantalum retaining ring crimped tightly to the edge of the puck, and with indium foil between the puck face and the sample for electrical and thermal contact. We chose GaAs substrate out of convenience because of its atomically smooth surface finish; and unlike silicon substrates, which are widely used in the community, GaAs has no native oxide layer. For high current beam delivery, molybdenum substrate has superior thermal conductivity, which should help to avoid QE degradation due to associated alkali loss by laser induced heating [21]. GaAs substrates, 600 micron-thick with $\langle 110\rangle$ cleave plane and p-doped with $\mathrm{Zn}\left(\sim 1 \times 10^{19} \mathrm{~cm}^{-3}\right)$, were cleaved to shape and installed on pucks without any chemical treatment. Molybdenum substrate, $1 \mathrm{~mm}$ thick, was hand polished with diamond paste to obtain a mirrorlike surface finish.

The photocathode fabrication process was as follows. First, a puck was placed on the bottom heater with the substrate facing up and heat cleaned at $450{ }^{\circ} \mathrm{C}$ for about 8 hours. The indium foil melts during the heat cycle providing good thermal contact between the puck and the substrate. Upon cooling to room temperature, the puck was transferred to the top heater with the substrate now facing down because the antimony pellets are held in place inside the heated crucible by gravity. The substrate was maintained at an elevated temperature during antimony deposition. As such, the top heater employs sapphire rollers attached to leaf springs that mate with a groove cut into the outer surface of the puck to securely hold it in place and to provide good mechanical contact to the heater surface. In addition, the top heater is attached to an electrically isolated linear translation stage to bias the puck at -280 volt in direct current during photocathode fabrication while positioning the puck approximately $3.8 \mathrm{~cm}$ above the evaporation sources-see Fig. 3 . The height of the activation mask was then set to $0.1 \mathrm{~cm}$ from the photocathode substrate.

The top heater maintains the substrate temperature at $120^{\circ} \mathrm{C}$ during antimony deposition. Antimony was evaporated for different durations by supplying $25 \mathrm{~A}$ to the tungsten heater coil wrapped around the crucible, and then retracted. The effusion source was then positioned below the photocathode and the heater power supply was discontinued as the cathode bias was turned on to monitor QE. The effusion source was preheated using hot nitrogen gas
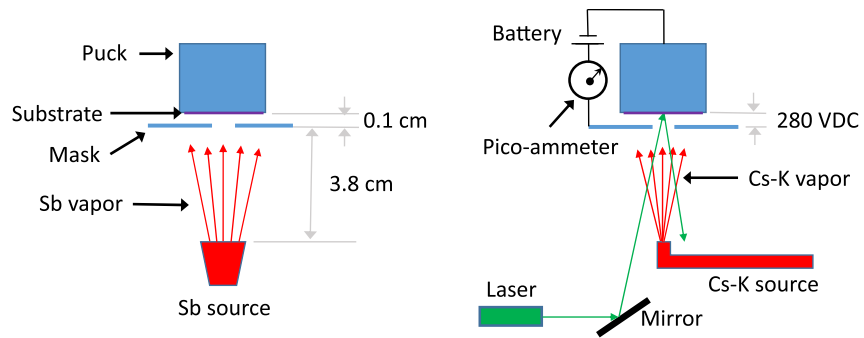

FIG. 3. Schematic of the fabrication. Two major steps of fabricating photocathodes. Left: deposition of Sb. Right: codeposition of $\mathrm{Cs}$ and $\mathrm{K}$. 


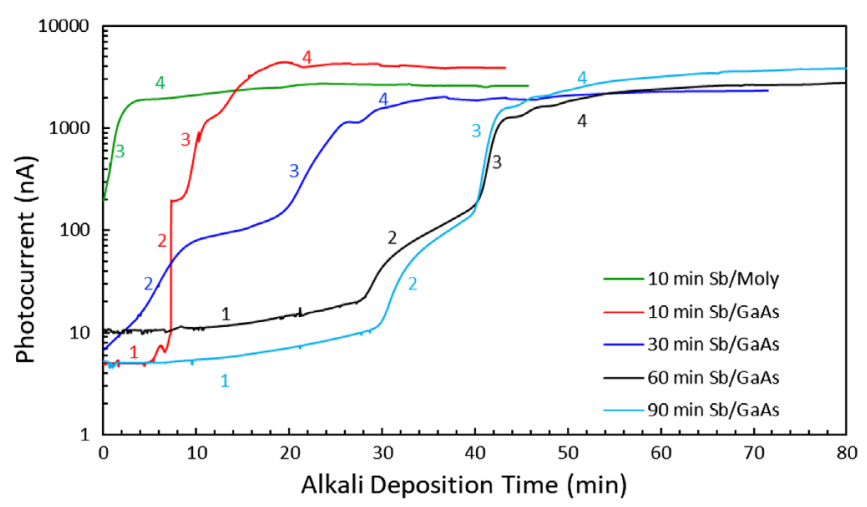

FIG. 4. Measured photocurrent versus alkali deposition time for photocathodes fabricated on GaAs and molybdenum substrates for different $\mathrm{Sb}$ deposition times. Stages 1, 2, 3, and 4 show the dominant processes in photocurrent evolution as described in the text.

passing through stainless-steel tubing brazed to the main Cs and $\mathrm{K}$ dispenser tube. A valve on the effusion source, in combination with the nitrogen gas temperature, was used to control the alkali source deposition rate. A residual gas analyzer served as a relative deposition monitor for the photocathode chemical species, as we did not have a crystal thickness monitor in the system. The QE of the photocathode was continuously monitored during fabrication using a low-power $532 \mathrm{~nm}$ laser, with alkali species applied to the photocathode until QE stopped increasing, and typical QE values in the range of 5\% to $10 \%$ were achieved. At this point, the substrate was cooled down by flowing dry nitrogen gas and the fabrication was complete. Once a photocathode was fabricated, it was transferred to the photogun or stored on one of the linear translation magnetic manipulators.

\section{PHOTOCATHODE CHARACTERISTICS}

The total time required to fabricate each photocathode varied as a function of antimony deposition time, which is correlated to antimony layer thickness. Figure 4 shows the evolution of photocurrent for each photocathode as a function of alkali-deposition time, with longer $\mathrm{Sb}$ deposition times requiring more alkali metal to achieve the highest QE. A summary of photocathode parameters including $\mathrm{Sb}$ and alkali deposition times is provided in Table I. The photocurrent at every stage is a cumulative effect of the dominant processes of all previous stages, and the stages are as follows: (i) diffusion of alkali in the $\mathrm{Sb}$ layer when the stoichiometry is alkali deficient; (ii) exothermic recrystallization of the Sb lattice; (iii) alkali enrichment and QE optimization; (iv) saturation, which will lead to $\mathrm{QE}$ decrease with a $\mathrm{Sb}$ deficient photocathode.

For $10 \mathrm{~min} \mathrm{Sb}$, the first two stages happened very quickly due to a thin Sb layer, supported by the EDS analysis summarized in Table IV. The third stage for the $10 \mathrm{~min} \mathrm{Sb} / \mathrm{GaAs}$ is shorter than the 60 and $90 \mathrm{~min}$ $\mathrm{Sb} / \mathrm{GaAs}$, again believed to be due to the thinner Sb layer. For $30 \mathrm{~min} \mathrm{Sb} / \mathrm{GaAs}$, this sample was fabricated on a previously used GaAs substrate. We believe that the heat cleaning, in addition to evaporating $\mathrm{Sb}, \mathrm{K}$ and $\mathrm{Cs}$ from the surface, also caused diffusion into the substrate. Although after heat cleaning the $\mathrm{QE}$ was zero, we believe there were some leftover diffused $\mathrm{Sb}$ and alkali materials. Therefore, the first step in $30 \mathrm{~min} \mathrm{Sb} / \mathrm{GaAs}$ sample was very brief and the $\mathrm{QE}$ of $30 \mathrm{~min} \mathrm{Sb} / \mathrm{GaAs}$ starts rising earlier than $10 \mathrm{~min} \mathrm{Sb} / \mathrm{GaAs}$.

The photocathode deposition chamber was not instrumented with a quartz crystal microbalance, the device commonly used to assign a thickness value to manufactured photocathodes, with "thickness" in the photocathode community typically referring to the thickness of the $\mathrm{Sb}$ foundational layer, and not the fully formed photocathode. So, although we cannot provide specific thickness values, from our past work [16], we believe the foundational $\mathrm{Sb}$ layer thickness varied by a factor larger than 50 (from $<20 \mathrm{~nm}$ to $>1 \mu \mathrm{m}$ ) across the range of $\mathrm{Sb}$ deposition times, 10 to 90 minutes.

The intention was to always grow photocathodes with the exact chemical composition, CsK2Sb, but in practice, QE was the parameter that was optimized, not chemical composition. Moreover, the two-chemical effusion source employed for alkali deposition provided no ability to selectively apply alkali elements independently.

TABLE I. Fabrication details and measurements of manufactured photocathodes.

\begin{tabular}{lcccccc}
\hline \hline Sample & Substrate & $\begin{array}{c}\text { Sb deposition } \\
\text { time (min) }\end{array}$ & $\begin{array}{c}\text { Alkali deposition } \\
\text { time (min) }\end{array}$ & QE (\%) & Reflectivity (\%) & $\begin{array}{c}\text { Index of } \\
\text { refraction }\end{array}$ \\
\hline 1 & GaAs & 10 & 10 & 5.2 & Not measured & \\
2 & GaAs & 30 & 53 & 5.2 & $26.4 \pm 0.4$ & 3.4 \\
3 & GaAs & 60 & 106 & 8.2 & $13.3 \pm 0.2$ & 2.3 \\
4 & GaAs & 90 & 96 & 6.3 & $14.6 \pm 0.3$ & 2.4 \\
5 & Mo & 10 & $\ldots 7$ & 8.3 & $9.1 \pm 0.1$ & 2.0 \\
Bare & Mo & $\ldots$ & $\ldots$ & $\ldots$ & $31.8 \pm 0.4$ & 3.9 \\
Bare & GaAs & $\ldots$ & $\ldots$ & $\cdots$ & $33.4 \pm 0.6$ & 4.1 \\
\hline \hline
\end{tabular}

${ }^{\mathrm{a}}$ The reported values of index of refraction assume specular reflection from a smooth photocathode surface, and ignore the possibility of enhanced reflectivity due to multiple reflections within the photocathode thin film. 
Alkali-antimonide photocathodes have unique indices of refraction, depending on composition. To gain insight into photocathode composition, the reflectivity of each photocathode was measured. The photogun design provides easy access to the reflected laser beam exiting the photogun vacuum chamber, with linear polarization oriented to provide maximum absorption (i.e., p-polarized light). Most of the alkali-antimonide photocathodes used for these studies were manufactured with limited active area, leaving a large amount of bare substrate exposed around the edge. As a check of methodology, the reflectivity of bare GaAs and molybdenum at $533 \mathrm{~nm}$ was measured (Table I), and the Fresnel equation for p-polarized light was used to calculate the index of refraction of these materials:

$$
\begin{aligned}
R_{p} & =\left|\frac{n_{1} \cos \theta_{t}-n_{2} \operatorname{con} \theta_{i}}{n_{1} \cos \theta_{t}+n_{2} \cos \theta_{i}}\right|^{2} \\
& =\left|\frac{n_{1} \sqrt{1-\left(\frac{n_{1}}{n_{2}} \sin \theta_{i}\right)^{2}}-n_{2} \operatorname{con} \theta_{i}}{n_{1} \sqrt{1-\left(\frac{n_{1}}{n_{2}} \sin \theta_{i}\right)^{2}}+n_{2} \cos \theta_{i}}\right|^{2},
\end{aligned}
$$

where $n_{1}$ is the index of refraction of vacuum $(=1), n_{2}$ represents the index of refraction of the substrate, and $\theta$ is the angle of incidence equal to $25^{\circ}$. Using measured reflectivity values, and solving for $n_{2}$ in Eq. (1), index of refraction values of 4.1 and 3.9 were obtained for GaAs and molybdenum, respectively, in reasonably good agreement with published values, 4.0 and 3.75 [26,27].

The published index of refraction for $\mathrm{CsK}_{2} \mathrm{Sb}$ is 3.6 [28] and would provide a reflectivity of about $32 \%$, assuming a smooth photocathode surface, a purely specular reflection, and ignoring the possibility of enhanced reflectivity due to multiple internal reflections within the photocathode thin film. Only the photocathodes grown on GaAs substrates and with short $\mathrm{Sb}$ deposition times provide reflectivity values approaching the expected $32 \%$ value. For the one photocathode grown on a molybdenum substrate, and for the photocathodes grown on GaAs with longer Sb deposition times, reflectivity was more representative of $\mathrm{Cs}_{3} \mathrm{Sb}$ photocathodes, or even bare antimony, with reported indices of refraction closer to $2[29,30]$.

Though we did not have access to a dedicated ellipsometry system [31] to accurately assess the index of refraction of the photocathode, our measurements of reflectivity suggest a complex process of stoichiometric evolution and the possibility that each photocathode evaluated in this study possessed a unique and varied chemical composition. Surface science measurements performed using EDS-SEM support this claim (see the Appendix), and suggest our photocathodes were K deficient, although the photocathodes tested in the EDS-SEM had to be transferred in air before evaluation which caused significant oxidation of the sample surface. Of course, the emittance measurements that form the basis of this work, and described below, speak indirectly to the surface roughness of photocathodes.

\section{DIAGNOSTIC BEAM LINE AND DRIVE LASER}

The photogun was connected to a 4-meter long diagnostic beam line with nominal $6.3 \mathrm{~cm}$ diameter aperture (Fig. 5). There are three diagnostic crosses with insertable yttrium aluminum garnet (YAG) crystal view screens, 100micron thick and $5 \mathrm{~cm}$ diameter. The electron beam strikes the YAG screen at normal incidence, and the fluorescent beam image is reflected to the CCD camera via a mirror mounted at $45^{\circ}$ behind YAG crystal. A wire scanner located upstream of the third diagnostic cross, consisting of a frame with a tensioned 20 micron-thick, $75 \%$ tungsten and $25 \%$

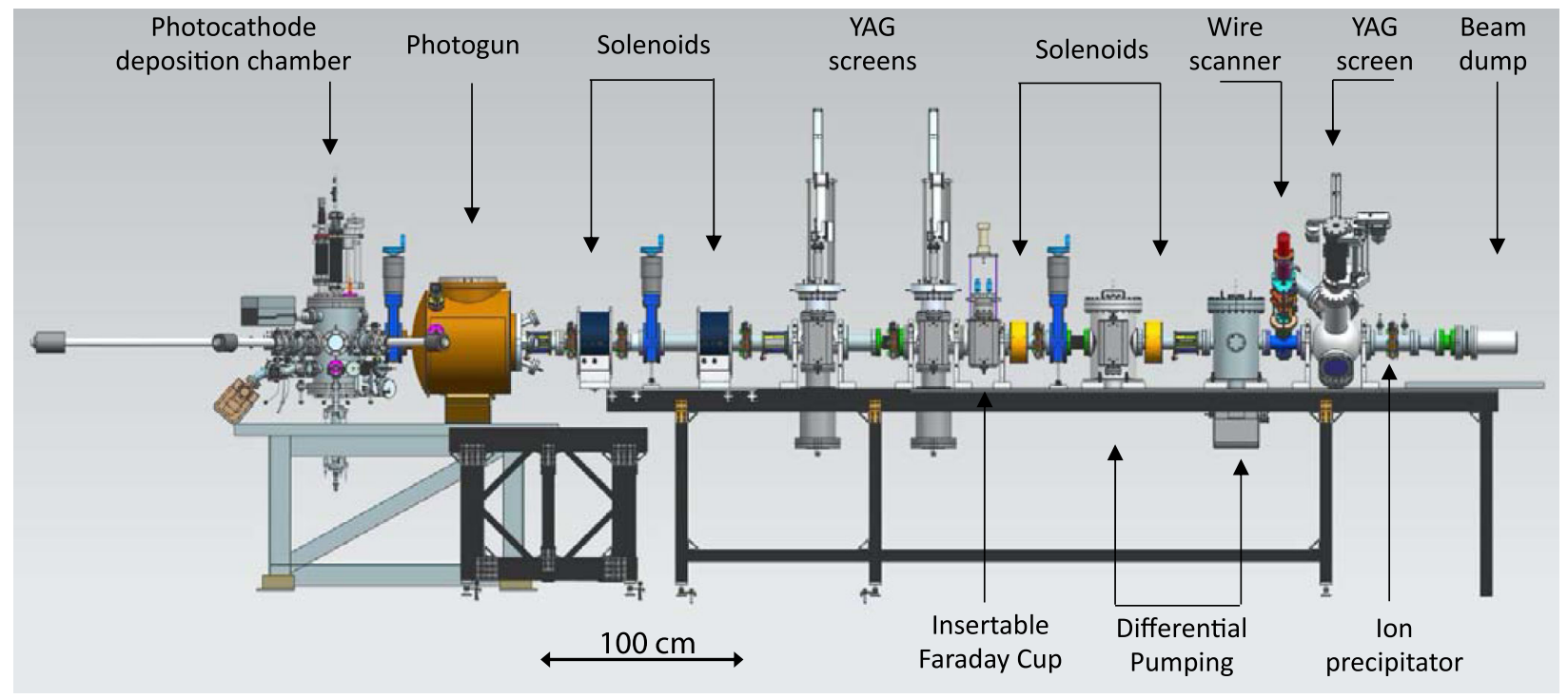

FIG. 5. Schematic of the photogun test stand and diagnostic beam line. 
rhenium wire, was used to measure the beam size. The photogun drive laser provided up to 3 Watts of power at $533 \mathrm{~nm}$, with 22 picoseconds rms optical pulses at $374.25 \mathrm{MHz}$ pulse repetition rate. Further details about the beam line and the drive laser can be found in Ref. [23].

\section{EMITTANCE MEASUREMENTS}

The solenoid scan formalism in Ref. [32] was implemented to find the beam moments from the measured $x, y$ rms beam sizes versus solenoid current, an example of which is shown in Fig. 6. The transfer matrix of the solenoid scan is expressed as $R \equiv R_{d} R_{\mathrm{foc}}$, where $R_{d}$ is the drift matrix and $R_{\text {foc }}$ is the focusing solenoid matrix. A rotation matrix was not employed in the calculation since the electron beam transverse profile was round. The expression for the expected $\mathrm{x}$-beam sizes squared is

$$
\begin{aligned}
x_{\mathrm{rms}}^{2}= & \left(C-L_{d} K S\right)^{2}\left\langle x^{2}\right\rangle+2\left(C-L_{d} K S\right)\left(S / K+C L_{d}\right)\left\langle x x^{\prime}\right\rangle \\
& +\left(S / K+C L_{d}\right)^{2}\left\langle x^{\prime 2}\right\rangle,
\end{aligned}
$$

where $\left\langle x^{2}\right\rangle,\left\langle x x^{\prime}\right\rangle$ and $\left\langle x^{2}\right\rangle$ are the beam moments at the solenoid entrance, and $K=\frac{e B_{0}}{2 \beta \gamma m c}$, L and $B_{0}$ are the strength, effective length and the peak magnetic field of the solenoid respectively, $L_{d}$ is the length of the drift, $C \equiv \cos (K L)$, and $S \equiv \sin (K L)$. A similar expression exists for y-beam sizes.

Emittance measurements were frequently made using both the YAG screens and the wire scanner diagnostics to cross compare and validate results. Beam emittance was first measured as a function of the photogun bias voltage, to study sensitivity of the YAG screens and wire scanner to the electron beam energy. It was noted that the signal from the wire scanner was nearly indistinguishable from background with the photogun biased at $-300 \mathrm{kV}$ because the secondary electron yield from the wire was comparable to the delivered beam current, leading to a net current of zero on the wire. Since both electron beam absorption in the wire and secondary electron yield from the wire depend on the incident electron beam energy, the emittance measurements described below were performed at $-200 \mathrm{kV}$ bias voltage where the two effects did not cancel one another. Next, the

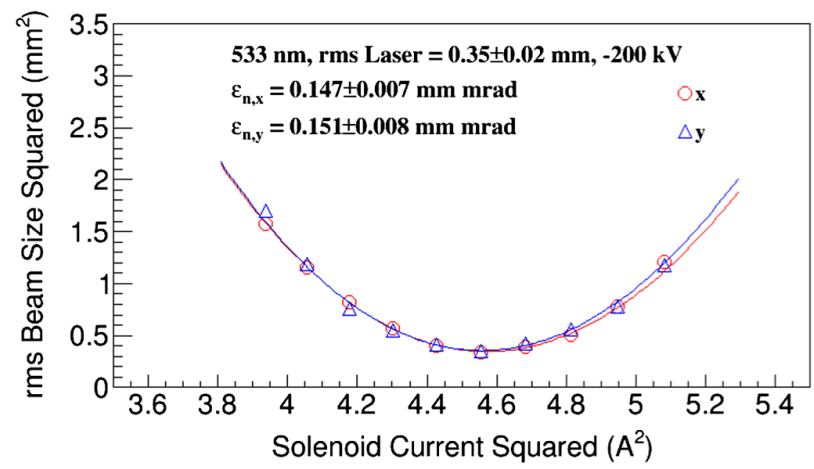

FIG. 6. A measurement of thermal emittance using a solenoid scan. beam emittance was measured as a function of average current and bunch charge to find beam current low enough that space charge is negligible, but high enough to be resolved by the wire scanner electronics. This current was achieved by adjusting the drive laser power and macropulse time structure to $250 \mu \mathrm{s}$ long pulses at $1.5 \%$ duty factor to generate $100 \mathrm{nA}$ average current resulting in about 20 femto-Coulomb bunch charge. The experimental results are shown in Fig. 7 and were obtained using the wire scanner to determine $x, y \mathrm{rms}$ beam sizes. Finally, the emittance was measured across the photocathode vertical and horizontal axes showing uniform beam emittance across a significant portion of the photocathode [23].

The solenoid scan method was then used to measure the photocathode thermal emittance. For these measurements, beam was generated from the center of the photocathode active area and a cylindrical focusing lens was used to adjust the laser beam spatial profile to account for the $25^{\circ}$ incident angle. The $x, y \mathrm{rms}$ beam sizes were obtained from the beam profile measured by the wire scanner and utilized in the vertical and horizontal emittance calculations and because the beam was always round, solenoid rotation matrices were not required. Figure 8 shows the results of

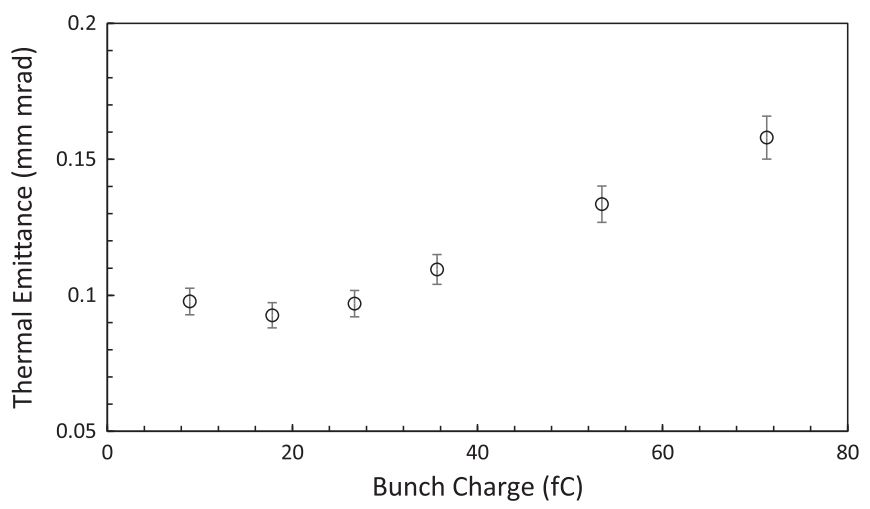

FIG. 7. Thermal emittance as a function of bunch charge at $-200 \mathrm{kV}$ bias voltage and $\mathrm{rms}$ laser spot size of $0.20 \mathrm{~mm}$.

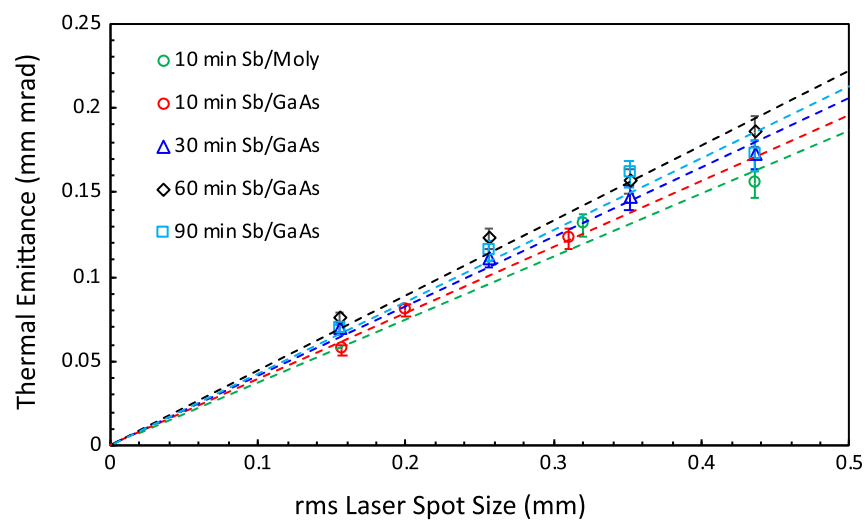

FIG. 8. Thermal emittance $x, y$ geometric mean versus laser spot size $(\sigma)$. 


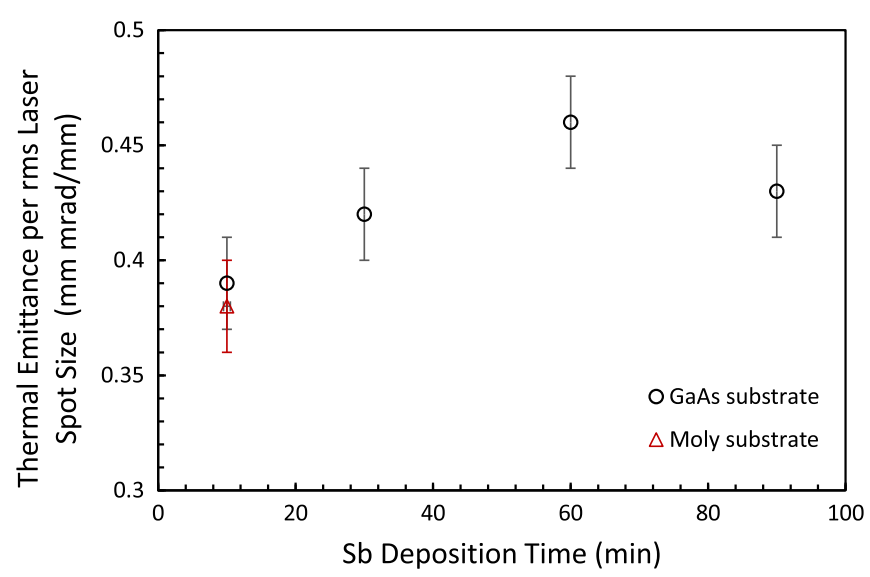

FIG. 9. Thermal emittance per rms laser spot size versus $\mathrm{Sb}$ deposition time with the smallest values obtained for the shortest $\mathrm{Sb}$ deposition time.

normalized thermal emittance $x, y$ geometric mean, $\varepsilon_{n}=\sqrt{\varepsilon_{x} \varepsilon_{y}}$, measured as a function of laser spot size using 20 femto-Coulomb bunch charge. The slope of each line fit represents the thermal emittance per rms laser spot size $(\sigma)$ for each sample with values shown in Fig. 9. The measured values of the thermal emittance per rms laser spot size were within 0.38 and $0.46 \mathrm{~mm} \mathrm{mrad} / \mathrm{mm}$, with the smallest values obtained for the shortest $\mathrm{Sb}$ deposition time.

\section{ROUGHNESS EMITTANCE OF PHOTOCATHODE SAMPLES}

In this work, the thermal emittance has two contributions: the smooth surface emittance due to the mean transverse energy (MTE) and the rough surface emittance and can be written as

$$
\frac{\varepsilon_{n}}{\sigma}=\sqrt{\left(\varepsilon_{M T E}\right)^{2}+\left(\varepsilon_{\text {roughness }}\right)^{2}} / \sigma .
$$

For a simple photoemission model, MTE is defined as

$$
M T E=\frac{\hbar \omega-E_{G}-E_{A}}{3} .
$$

With photon energy $\hbar \omega=2.33 \mathrm{eV}$ and using values from Ref. [4] for $\mathrm{CsK}_{2} \mathrm{Sb}$ photocathode (band gap energy
$E_{G}=1.0 \mathrm{eV}$ and electron affinity $\left.E_{A}=1.1 \mathrm{eV}\right), M T E$ is $0.075 \mathrm{eV}$ and $\frac{\varepsilon_{M T E}}{\sigma}=\sqrt{\frac{M T E}{m_{0} c^{2}}}=0.39 \mathrm{~mm} \mathrm{mrad} / \mathrm{mm}$ where $m_{0}$ is the electron rest mass and $c$ is the speed of light. We have not measured the band gap energy nor the electron affinity of our photocathodes where both depend on the detailed stoichiometry of the cathode. Any discrepancy will most likely be due to different stoichiometry of our photocathodes (see Table IV) compared to those studied by other groups.

Assuming smooth surface emittance per rms laser spot size of $0.39 \mathrm{~mm} \mathrm{mrad} / \mathrm{mm}$, Eq. (3) can be used to calculate the roughness emittance per rms laser spot size indicating a value as large as $0.24 \mathrm{~mm} \mathrm{mrad} / \mathrm{mm}$. Furthermore, the roughness emittance can be written as

$$
\frac{\varepsilon_{\text {roughness }}}{\sigma}=\sqrt{\frac{X_{g} e E}{3 m_{0} c^{2}}},
$$

where $X_{g}$ is the geometry factor of the roughness emittance [33], $e$ is the electron charge and $E$ is the electric field strength $(1.5 \mathrm{MV} / \mathrm{m}$ with the cathode biased at $-200 \mathrm{kV})$. Table I shows the roughness emittance and the corresponding geometry factor for the tested photocathode samples.

We summarize the correlation between thermal emittance per rms laser spot size and Sb deposition time in Table II. Emittance and potentially roughness increase with $\mathrm{Sb}$ deposition time, and therefore $\mathrm{Sb}$ thickness, consistent with past studies of the bare Sb foundational layer [16,34]. However, the correlation is relatively small, especially at the rather small electric field strength we have in our photogun, and nothing like what was implied by our past measurements which showed crystal formation with rough surfaces possessing micron-size dimensions for long $\mathrm{Sb}$ deposition times. The relative insensitivity of emittance to $\mathrm{Sb}$ deposition time/thickness detailed in Table II supports observations made at $\mathrm{x}$-ray light sources, namely an exothermic reaction takes place during photocathode fabrication that completely transforms the Sb layer [18]. Due to the exothermic reaction of alkali with $\mathrm{Sb}$, the photocathode thickness becomes vastly different from the initial Sb layer thickness. During the exothermic reaction

\begin{tabular}{|c|c|c|c|c|}
\hline Substrate & $\begin{array}{l}\text { Sb deposition } \\
\text { time (min) }\end{array}$ & $\begin{array}{l}\text { Thermal emittance per } \\
\text { rms laser spot size, } \\
\frac{\varepsilon_{n}}{\sigma}(\mathrm{mm} \mathrm{mrad} / \mathrm{mm})\end{array}$ & $\begin{array}{l}\text { Roughness emittance per } \\
\text { rms laser spot size, } \\
\frac{\varepsilon_{\text {roughness }}}{\sigma}(\mathrm{mm} \mathrm{mrad} / \mathrm{mm})\end{array}$ & $\begin{array}{c}\text { Geometry factor of } \\
\text { roughness emittance, } \\
X_{g}(\mathrm{~nm}) \\
\end{array}$ \\
\hline GaAs & 10 & $0.39 \pm 0.02$ & $<0.09$ & $<8$ \\
\hline GaAs & 30 & $0.42 \pm 0.02$ & $0.16 \pm 0.05$ & $26 \pm 16$ \\
\hline GaAs & 60 & $0.46 \pm 0.02$ & $0.24 \pm 0.04$ & $59 \pm 20$ \\
\hline GaAs & 90 & $0.43 \pm 0.02$ & $0.18 \pm 0.05$ & $33 \pm 18$ \\
\hline Molybdenum & 10 & $0.38 \pm 0.02$ & $<0.04$ & $<3$ \\
\hline
\end{tabular}
process the Sb structure changes $[6,8,34]$ which results in

TABLE II. Thermal emittance, roughness emittance and geometry factor values for the tested photocathode samples. 
TABLE III. Photocathode charge lifetime summary.

\begin{tabular}{lcccc}
\hline \hline Substrate & $\begin{array}{c}\text { Sb deposition } \\
\text { time (min) }\end{array}$ & $\begin{array}{c}\text { Electron beam } \\
\text { current (mA) }\end{array}$ & $\begin{array}{c}\text { Run-time } \\
\text { (hour) }\end{array}$ & $\begin{array}{c}\text { Charge } \\
\text { lifetime (C) }\end{array}$ \\
\hline GaAs $^{\text {a }}$ & 10 & 4.5 & 6 & 160 \\
GaAs $^{b}$ & 30 & 1.0 & 6 & 120 \\
GaAs & 60 & 1.0 & 9 & 40 \\
GaAs & 90 & 4.5 & 10 & 6600 \\
Molybdenum & 10 & 4.5 & 11 & No QE decay \\
\hline \hline
\end{tabular}

${ }^{\text {a }}$ The lifetime measurement for sample $10 \mathrm{~min} \mathrm{Sb} / \mathrm{GaAs}$ was performed before extensive work on the system, and may reflect conditions within the vacuum system rather than inherent photocathode properties.

${ }^{\mathrm{b}}$ The $30 \mathrm{~min} \mathrm{Sb} / \mathrm{GaAs}$ sample was heat cleaned, resulting in photocathode material diffusing into the GaAs and affecting results.

minimizing the voids in Sb grains, improving the compactness of the photocathode film, and reducing the ultimate thickness of the photocathode with respect to the initial $\mathrm{Sb}$ layer. Our beam-based emittance studies support this observation, since our photocathodes manufactured with relatively thick $\mathrm{Sb}$ layers can provide emittance low enough for many applications. There are other applications, such as XFELs, where the smallest lasing wavelength is limited by the thermal emittance of the electron beam at the cathode [35] and emittances of $0.4 \mathrm{~mm} \mathrm{mrad} / \mathrm{mm}$ are not sufficient.

\section{PHOTOCATHODE CHARGE LIFETIME}

Fabricating photocathodes that provide long photogun operational lifetime is especially important for applications requiring very high average current. Charge lifetime is a useful photocathode metric defined as the amount of charge that can be extracted before QE falls to 1/e of the initial value. Some electron cooling proposals require beam current greater than $100 \mathrm{~mA}[35,36]$, however for these studies, beam current was limited by the high voltage power supply $5 \mathrm{~mA}$ limit. As described in Ref. [23], uninterrupted beam delivery from the photogun was only

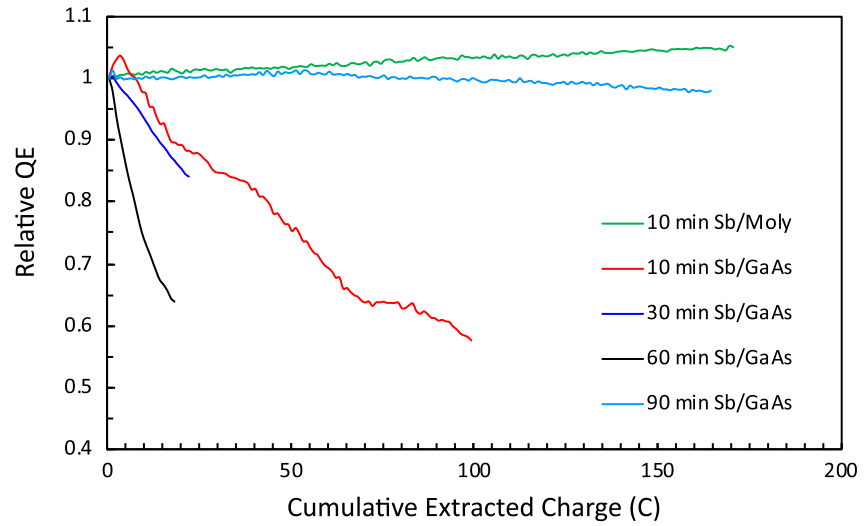

FIG. 10. Relative QE (relative to the initial value during lifetime measurement) versus the cumulative extracted charge for the five fabricated photocathodes. possible when a positive bias voltage was applied to the photogun anode electrode.

Table III summarizes the charge lifetime measurements for beam delivery under various conditions for the five fabricated photocathodes, each fabricated with an active area centered off axis by 1 to $2 \mathrm{~mm}$ relative to the photocathode substrate center. The laser spot position was in the center of the photocathode active area and its size was $0.4 \mathrm{~mm}$ rms. The larger laser spot size was used to prevent overheating the photocathode due to high laser power intensity.

The highest charge lifetime from samples grown on GaAs was $6600 \mathrm{C}$, and was obtained from the photocathode with 90 minute $\mathrm{Sb}$ deposition time operating at $4.5 \mathrm{~mA}$ average current and $0.55 \mathrm{~A}$ peak current at the photocathode. Charge lifetime was best for the $\mathrm{Cs}_{x} \mathrm{~K}_{y} \mathrm{Sb}$ photocathode grown on a molybdenum substrate. In fact, charge lifetime was difficult to measure because QE was often observed to slowly increase during the run, and because the charge extracted during the run was comparatively small. Figure 10 shows the relative $\mathrm{QE}$ of the five fabricated photocathodes versus the cumulative extracted charge.

Several factors make direct comparison of the lifetimes for the $\mathrm{Sb} / \mathrm{GaAs}$ samples difficult to compare. The first sample (10 min $\mathrm{Sb} / \mathrm{GaAs}$ ) was fabricated and tested in the photogun about a year earlier than the rest of samples included in this study, prior to significant changes to the vacuum system. Additionally, the $30 \mathrm{~min} \mathrm{Sb} / \mathrm{GaAs}$ sample was fabricated on a previously used GaAs substrate, where the heat cleaning resulted in the diffusion of photocathode materials into the substrate, affecting the behavior. For these reasons, when comparing only the results for photocathodes grown on GaAs substrates, there is no discernible trend based on $\mathrm{Sb}$ deposition time.

\section{CONCLUSION}

The thermal emittance per rms laser spot size of $\mathrm{Cs}_{x} \mathrm{~K}_{y} \mathrm{Sb}$ photocathodes increased only slightly as a function of photocathode thickness. While the exact thickness of each photocathode was not measured, we estimate that 
the thickness of the $\mathrm{Sb}$ foundational layer varied by at least a factor of 50 and likely much more across the range of $\mathrm{Sb}$ deposition times, 10 to 90 minutes.

We observed that thermal emittance is relatively insensitive to $\mathrm{Sb}$ thickness, consistent with studies performed by others that indicate the $\mathrm{Sb}$ foundational layer is completely transformed during the exothermic photocathode fabrication process. Our measurements suggest it is not critical to grow a thin photocathode in order to obtain low emittance when using standard sequential growth techniques, since the alkali deposition strongly changes the $\mathrm{Sb}$ foundational layer morphology. Even more true if the electric field gradient at the photocathode is rather low as it is the case for dc HV photoguns. However, this could be an issue with rf photoguns where the electric field strength is very large.

Photocathode reflectivity varied significantly over the set of manufactured photocathodes, which likely speaks to a significant variation in photocathode stoichiometry stemming from different $\mathrm{Sb}$ foundational layer thickness, but also which substrate was employed and the growth condition. Although performed after transporting the used photocathodes through air, surface science evaluation using EDS-SEM (Appendix below) supports speculation that our photocathodes-particularly the ones grown on GaAs-were potassium deficient, with chemical composition closer to $\mathrm{Cs}_{3} \mathrm{Sb}$ than $\mathrm{CsK}_{2} \mathrm{Sb}$. The effusion source containing both alkali species provides convenience but does not provide a means to independently vary the alkali concentration of each element. For future photocathode studies, the Jefferson Lab alkali-antimonide deposition chamber will be modified to include separate alkali sources and a quartz-crystal microbalance to provide a thickness assessment similar to values reported community wide.

The photocathode grown on GaAs with 90 min $\mathrm{Sb}$ deposition demonstrated enhanced operational lifetime compared to the ones with less $\mathrm{Sb}$ deposition on GaAs. This agrees with our past observation that thicker Sb layers lead to longer operational lifetime [25]. The photocathode grown on molybdenum yielded the longest operational lifetime even with a short $\mathrm{Sb}$ deposition time. From our previous work [21], the two dominant mechanisms causing QE decay are ionized residual gasses striking the photocathode (ion back bombardment), and chemical desorption due to heating caused by the high laser power needed to deliver high beam currents. The desorbed atoms can further get ionized by the emitted electrons and generate ions that can reinforce the debilitating effect of ion back bombardment. The superior beam operational lifetime achieved from the sample prepared on the molybdenum substrate, which has high thermal conductivity, supports the theory that minimizing heating is essential for continuous delivery of high beam currents from an alkali antimonide photocathode.

\section{ACKNOWLEDGMENTS}

This paper was authored by Jefferson Science Associates, LLC under U.S. DOE Contract No. DE-AC05-06OR23177 and supported by Laboratory Directed Research and Development funding. We are grateful for useful comments and suggestions from Dr. John Smedley.

\section{APPENDIX: SURFACE SCIENCE EVALUATION OF PHOTOCATHODE COMPOSITION}

The intention was to always fabricate photocathodes with the precise ratio of chemical species; $\mathrm{Cs}, \mathrm{K}$ and $\mathrm{Sb}$ with relative concentrations $1: 2: 1$, but it was not possible to precisely control the concentration of the alkali species, especially because $\mathrm{Cs}$ and $\mathrm{K}$ originate from the same effusion source at the same temperature. After finishing the beam-based studies, the photocathodes were removed from the photogun and transferred in air to an energy dispersive $\mathrm{x}$-ray spectroscopy used in conjunction with a scanning electron microscope (EDS-SEM, Noran System Six by Thermo Electron and JSM-6060LV by JEOL) apparatus to determine chemical composition. Exposure to air results in a heavily oxidized surface such that the samples studied in the EDS-SEM are not precisely the samples used to generate electron beam. Nonetheless, a comparative assessment of chemical composition performed in this manner was still deemed useful.

Table IV summarizes the chemical composition of four photocathodes with analysis performed at multiple locations on each photocathode. The results are the average of the points analyzed. Overall, the ratio of $\mathrm{Cs}$ to $\mathrm{K}$ was much higher than desired for photocathodes grown on GaAs substrates compared to the photocathode grown on molybdenum: photocathodes grown on GaAs substrates are potassium deficient, whereas the photocathode grown on molybdenum has very nearly the desired $\mathrm{Cs} / \mathrm{K}$ ratio, which may help explain why the photocathode grown on molybdenum exhibited the best $\mathrm{QE}$ and the highest charge

TABLE IV. Chemical composition of photocathodes after exposure to air during installation in the EDS-SEM machine. The intended ratio of chemical species $\mathrm{Cs}, \mathrm{K}$ and $\mathrm{Sb}$ was $1: 2: 1$. Alkali element concentrations were normalized to the concentration of $\mathrm{Sb}$, which was set to "1". Sb peak was too low to be identified by the EDS-SEM for the photocathode grown on the molybdenum substrate and the concentration of $\mathrm{K}$ was used for normalization is this case.

\begin{tabular}{lccccc}
\hline \hline Substrate & $\begin{array}{c}\text { Sb deposition } \\
\text { time (min) }\end{array}$ & {$[\mathrm{Cs}]$} & {$[\mathrm{K}]$} & {$[\mathrm{Cs}] /[\mathrm{K}]$} & {$[\mathrm{Sb}]$} \\
\hline Ideal composition & & 1 & 2 & 0.50 & 1 \\
GaAs & 30 & 1.92 & 0.70 & 2.74 & 1 \\
GaAs & 60 & 1.16 & 0.56 & 2.07 & 1 \\
GaAs & 90 & 1.38 & 0.54 & 2.56 & 1 \\
Molybdenum & 10 & 0.72 & 1 & 0.72 & $\ldots$ \\
\hline \hline
\end{tabular}


lifetime. Interestingly, the EDS-SEM could not detect the $\mathrm{Sb}$ element for the photocathode grown on the molybdenum. It should also be mentioned that this sample exhibited low reflectivity, which was comparable to the reflectivity of samples grown on GaAs that were deemed the thickest.

[1] M. Altarelli et al., The European x-ray free electron laser technical design report, Report No. DESY 2006-97, 2007.

[2] H. Abe et al., Energy Recovery Linac Conceptual Design Report, KEK Report No. 2012-4, 2012.

[3] Y.S. Derbenev, Theory of electron cooling, arXiv: 1703.09735.

[4] D. H. Dowell, I. Bazarov, B. Dunham, K. Harkay, C. Hernandez-Garcia, R. Legg, H. Padmore, T. Rao, J. Smedley, and W. Wan, Cathode R\&D for future light sources, Nucl. Instrum. Methods Phys. Res., Sect. A 622, 685 (2010).

[5] X. Wang and Y. Li, Ultrafast electron diffraction, Chin. Phys. B 27, 7 (2018), https://iopscience.iop.org/article/10 .1088/1674-1056/27/7/076102.

[6] S. Schubert, J. Wong, J. Feng, S. Karkare1, H. Padmore, M. Ruiz-Osés, J. Smedley, E. Muller, Z. Ding, Mengjia, Gaowei, K. Attenkofer, X. Liang, J. Xie, and J. Kühn, Bi-alkali antimonide photocathode growth: An X-ray diffraction study, J. Appl. Phys. 120, 035303 (2016).

[7] RP Photonics Encyclopedia-Photocathodes, https://www .rp-photonics.com/photocathodes.html.

[8] S. Schubert, M. Ruiz-Osés, I. Ben-Zvi, T. Kamps, X. Liang, E. Muller, K. Müller, H. Padmore, T. Rao, X. Tong, T. Vecchione, and J. Smedley, Bi-alkali antimonide photocathodes for high brightness accelerators, APL Mater. 1, 032119 (2013).

[9] J. Smedley, K. Attenkofer, S. G. Schubert, H. A. Padmore, J. Wong, J. Xie, M. Ruiz-Oses, I. Ben-Zvi, X. Liang, E. M. Muller, and J. DeFazio, Alkali antimonide photocathodes for everyone, in Proceedings of the 25th Particle Accelerator Conference, PAC-2013, Pasadena, CA, 2013 (IEEE, New York, 2013), THPAC17, p. 1178.

[10] D. E. Persyk, J. Morales, R. McKeighen, and G. Muehllehner, The quadrant photomultiplier, IEEE Trans. Nucl. Sci. 26, 364 (1979).

[11] J. Smedley, M. Gaowei, J. Sinsheimer, K. Attenkofer, J. Walsh, S. Schubert, J. Wong, H. Padmore, J. Kuhn, E. Muller, Z. Ding, H. Frisch, H. B. Bhandari, H. Lingertat, V. Wang, O. Ovechkina, and V. V. Nagarkar, Sputter growth of alkali antimonide photocathodes: An in operando materials analysis, in Proceedings of the 6th International Particle Accelerator Conference, Richmond, VA, 2015 (JACoW, Geneva Switzerland, 2015), TUPHA003, pp. 1965-1967.

[12] L. Cultrera et al., Photocathode behavior during high current running in the Cornell energy recovery linac photoinjector, Phys. Rev. ST Accel. Beams 14, 120101 (2011).

[13] S. Schubert, J. Wong, J. Feng, S. Karkare, H. Padmore, M. Ruiz-Osés, J. Smedley, E. Muller, Z. Ding, M. Gaowei, K. Attenkofer, X. Liang, J. Xie, and J. Kühn, Bi-alkali antimonide photocathode growth: An x-ray diffraction study, J. Appl. Phys. 120, 035303 (2016).
[14] L. Cultrera, I. V. Bazarov, J. V. Conway, B. Dunham, S. Karkare, Y. Li, X. Liu, J. M. Maxson, and K. W. Smolenski, Growth and characterization of bialkali photocathodes for Cornell ERL injector, in Proceedings of the 24th Particle Accelerator Conference, PAC-2011, New York, 2011 (IEEE, New York, 2011), WEP244.

[15] M. A. Mamun, M. R. Hernandez-Flores, E. Morales, C. Hernandez-Garcia, and M. Poelker, Temperature dependence of alkali-antimonide photocathodes: Evaluation at cryogenic temperatures, Phys. Rev. Accel. Beams 20, 103403 (2017).

[16] M. A. A. Mamun, A. A. Elmustafa, C. Hernandez-Garcia, R. Mammei, and M. Poelker, Effect of Sb thickness on the performance of bialkali-antimonide photocathodes, J. Vac. Sci. Technol. A 34, 021509 (2016).

[17] J. Feng, S. Karkare, J. Nasiatka, S. Schubert, J. Smedley, and H. Padmore, Near atomically smooth alkali antimonide photocathode thin films, J. Appl. Phys. 121, 044904 (2017).

[18] I. Bazarov, L. Cultrera, A. Bartnik, B. Dunham, S. Karkare, Y. Li, X. Liu, J. Maxson, and W. Roussel, Thermal emittance measurements of a cesium potassium antimonide photocathode, Appl. Phys. Lett. 98, 224101 (2011).

[19] T. Vecchione, I. Ben-Zvi, D. H. Dowell, J. Feng, T. Rao, J. Smedley, W. Wan, and H. A. Padmore, A low emittance and high efficiency visible light photocathode for high brightness accelerator-based X-ray light sources, Appl. Phys. Lett. 99, 034103 (2011).

[20] T. Vecchione, J. Feng, W. Wan, H. A. Padmore, I. Ben-Zvi, X. Liang, M. Ruiz-Oses, T. Rao, J. Smedley, and D. Dowell, Effect of roughness on emittance of potassium cesium antimonide photocathodes, in Proceedings of the 3rd International Particle Accelerator Conference, New Orleans, LA, 2012 (IEEE, Piscataway, NJ, 2012).

[21] R. R. Mammei, R. Suleiman, J. Feingold, P. A. Adderley, J. Clark, S. Covert, J. Grames, J. Hansknecht, D. Machie, and M. Poelker, Charge lifetime measurements at high average current using a $\mathrm{K}_{2} \mathrm{CsSb}$ photocathode inside a dc high voltage photogun, Phys. Rev. ST Accel. Beams 16, 033401 (2013).

[22] M. Gaowei, Z. Ding, S. Schubert, H. B. Bhandari, J. Sinsheimer, J. Kuehn, V. V. Nagarkar, M. S. J. Marshall, J. Walsh, E. M. Muller, K. Attenkofer, H. J. Frisch, H. Padmore, and J. Smedley, Synthesis and X-ray characterization of sputtered bi-alkali antimonide photocathodes, APL Mater. 5, 116104 (2017).

[23] C. Hernandez-Garcia et al., Compact-300 kV dc inverted insulator photogun with biased anode and alkali-antimonide photocathode, Phys. Rev. Accel. Beams 22, 113401 (2019).

[24] C. Hernandez-Garcia, D. Bullard, F. Hannon, Y. Wang, and M. Poelker, High voltage performance of a dc photoemission electron gun with centrifugal barrel-polished electrodes, Rev. Sci. Instrum. 88, 093303 (2017).

[25] M. A. Mamun, C. Hernandez-Garcia, M. Poelker, and A. A. Elmustafa, Correlation of $\mathrm{CsK}_{2} \mathrm{Sb}$ photocathode lifetime with antimony thickness, APL Mater. 3, 066103 (2015).

[26] J. O. Akinlami and A. O. Ashamu, Optical properties of GaAs, J. Semicond. 34, 032002 (2013. 
[27] Refractive Index Database, FILMETRICS, KLA Corporation, https://www.filmetrics.com/refractive-index-database.

[28] M. E. Moorhead and N. W. Tanner, Optical properties of an EMI $\mathrm{K}_{2} \mathrm{CsSb}$ bialkali photocathode, Nucl. Instrum. Methods Phys. Res., Sect. A 378, 162 (1996).

[29] T. Shima, J. Kim, J. Tominaga, and N. Atoda, Refractive indices change at $633 \mathrm{~nm}$ of antimony thin films prepared by heliconwave-plasma sputtering method, J. Vac. Sci. Technol. A 19, 826 (2001).

[30] J. M. Barios, C. fouassier, M. Onillon, and B. Tanguy, Experimental study of the nonstoichiometry of cesium antimonide $\approx \mathrm{Cs}_{3} \mathrm{Sb}$, Mater. Chem. Phys. 24, 18 (1989), https://jglobal.jst.go.jp/en/detail?JGLOBAL_ID=2009020 18989856918.

[31] D. Motta and S. Schönert, Optical properties of bialkali photocathodes, Nucl. Instrum. Methods Phys. Res., Sect. A 539, 217 (2005).

[32] L. Zheng, J. Shao, Y. Du, J. G. Power, E. E. Wisniewski, W. Liu, C. E. Whiteford, M. Conde, S. Doran, C. Jing, C. Tang, and W. Gai, Overestimation of thermal emittance in solenoid scans due to coupled transverse motion, Phys. Rev. Accel. Beams 21, 122803 (2018).
[33] H. J. Qian, C. Li, Y. C. Du, L. X. Yan, J. F. Hua, W. H. Huang, and C.X. Tang, Experimental investigation of thermal emittance components of copper photocathode, Phys. Rev. ST Accel. Beams 15, 040102 (2012).

[34] M. Ruiz-Osés, S. Schubert, K. Attenkofer, I. Ben-Zvi, X. Liang, E. Muller, H. Padmore, T. Rao, T. Vecchione, J. Wong, J. Xie, and J. Smedley, Direct observation of bi-alkali antimonide photocathodes growth via in operando x-ray diffraction studies, APL Mater. 2, 121101 (2014).

[35] M. Poelker, P. Adderley, J. Benesch, B. Bullard, J. Grames, F. Hannon, J. Hansknecht, C. Hernandez-Garcia, R. Kazimi, G. Krafft, M. A. Mamun, R. Suleiman, M. Tiefenback, Y. Wang, S. Wijiethunga, J. Yoskovitz, and S. Zhang, Magnetized electron beam for JLEIC recirculator cooler ring, in Proceedings of Science (2018), XVII International Workshop on Polarized Sources, Targets \& Polarimetry (Kaist, South Korea, 2017).

[36] J. Ma, X. Wang, G. Wang, K. Yu, R. Samulyak, and V. Litvinenko, Electron Simulation studies of modulator for coherent electron cooling, Phys. Rev. Accel. Beams 21, 111001 (2018). 